\title{
Effectiveness of Traffic Forecasting on Pavement Designs for Sri Lankan Roads
}

\author{
W. K. Mampearachchi and P. H. Gunasinghe
}

\begin{abstract}
Pavement design plays an important role in any improvement or rehabilitation. It is a responsibility of the road design Engineer to ensure that he has come up with an effective design, so that it will last for the design life. This effectiveness or the optimization is very important as otherwise it could lead to financial implications.

The method adopted for the design of flexible pavements is the TRL, Road Note 31. The two main parameters considered in the design of the pavements under Road Note 31 are Cumulative Number of Standard Axles (CNSA) (i.e. Traffic Class) and the sub-grade strength (i.e. California Bearing Ratio (CBR)\% class).

In this research study, flexible pavement designs of recently rehabilitated or improved set of roads were analyzed to check the effectiveness of the traffic forecasting on pavement design. As the subgrade strength of the pavements is a fixed parameter in all the cases, the only possible variable is the Traffic Class relevant to predicted CNSA.

It was found in the study that the actual traffic growth rates of different modes of traffic which travels along the selected roads is different to the predicted rates at the time of design. It has also been shown and statistically proved that the Equivalent Standard Axles (ESA) values actually applied on these pavements by large trucks / heavy goods vehicles are significantly high, compared to the ESA values recorded at the design stage. The authors have proposed a methodology to evaluate the effectiveness of traffic forecasting on pavement designs, and improvements to the present practice of pavement designs carried out by the Road Development Authority (RDA) and its presentation.
\end{abstract}

Keywords: $\quad$ Pavement Designs, Sri Lankan roads

\section{Introduction}

The damage that vehicles cause to a road depends very strongly on the axle loads of the vehicles. For pavement design purposes the damaging power of axles is related to a 'standard' axle of 8.16 tonnes using equivalence factors which have been derived from empirical studies [1,2]

The method adopted for the design of flexible pavements is similar to the Transport Research Laboratory (TRL), Road Note 31,[3]. The two main parameters considered in the design of the pavements under Road Note 31 are Cumulative Number of Standard Axles (CNSA) and the sub-grade strength [3]. The design of rigid pavements is carried out as [4]. The deterioration of paved roads caused by traffic is due to both the magnitude of the individual wheel loads and the number of times these loads are applied. For pavement design purposes, it is therefore necessary to consider not only the total number of vehicles that will use the road, but also the vehicle wheel or axle loads. Hence, both traffic count and axle load information are essential for pavement design purposes.

In many countries, road traffic is growing rapidly in volume and in the size and weight of the vehicles using the roads. As a consequence, highway engineers concerned with designing new roads or the strengthening of existing roads require reliable information about the distribution of axle loads for existing traffic as well as information on National or regional axle load trends. This information is required, so that accurate forecasts can be made of the axle loads that a road will have to carry over its design life.

\footnotetext{
Eng. (Dr.) W. K. Mampearachchi, BSc. Eng.(Hons)(Moratuwa), MIE (Sri Lanka), MSCE (South Florida), PhD (Florida), CMILT (UK), Senior Lecturer, Department of Civil Engineering, University Moratuwa, Katubedda, Moratuwa, Sri Lanka.

Eng. P. H. Gunasinghe., B.Sc. Eng. (Moratuwa), M.Eng. (Highway \& Traffic, Moratuwa), MIE(Sri Lanka), Chief Engineer, Road Development Authority.
} 
Since the pavement design plays an important role in any improvement or rehabilitation, it is a responsibility of the road design Engineer to ensure that he has come up with an effective design, so that it will last for the design life. This effectiveness or the optimization is very important as otherwise it could lead to financial implications. If it is under designed, it will not last till the end of its design life, thereby incurring huge sums of money for the early rehabilitation and maintenance.

If it is over designed, that would also be an undesirable fact, as the cost over run on this could have been utilized to improve another few kilometers of road.

\section{Significance of the Problem}

If pavements are to be designed adequately, the importance of accurate knowledge about the magnitude and frequency of the axle loads being carried on the roads is self-evident. When any road project is being designed, or appraised at the feasibility stage, it is recommended that a classified traffic count and an axle load survey of commercial vehicles are undertaken. Ideally, such surveys should be carried out several times during the year to reflect seasonal changes [5] in the numbers of vehicles and the magnitude of the loads.

In the Sri Lankan context, it expends a large sum of money on the improvements and the maintenance of the existing road network. Every year, a substantial percent of GDP is allocated for the road sector. As far as the present economic situation of the country is concerned, this allocation is inadequate to meet the expenditure required for the rehabilitation and improvements of the present road network. Hence, the country has to depend on foreign investments, grants and loans for the further improvements and the development of the road sector. The situation has further worsened, as the country is facing an economic crisis. The allocated funds sometimes do not meet even the urgent rehabilitation and maintenance of the entire road network.

In view of the above, there is a need to utilize the limited allocated funds in an effective manner. It is therefore, necessary to make sure that there are well disciplined procedures in the planning, design, construction, monitoring and maintenance of the entire road network.

\section{Present Practice of Pavement Design/Traffic Forecasting}

Generally, for the rehabilitation or the road improvement projects funded by the Government of Sri Lanka, the pavement designs are done by the Road Development Authority (RDA). The present method of design is based on the Transport Research Laboratory method [3], but modified to suit local conditions. The method covers roads carrying traffic up to 30 million standard axles during the design period [6]. Also, the specifications for the materials to be used in the various pavement layers are as specified in the standard specifications of RDA.[7] It was found that in most of the occasions the ESA values have been assumed or else typical values for ESA in designs for RDA roads have been used. Sometimes ADT/MCC data used for the designs were out dated. It was also noted that there is no standard or consistency in the design reports. These depend on the design Engineer.

Despite, some improvements have been done for the pavement designs by RDA; it is normally assumed the year of construction (two to three years assumed from the design year) and also uses ESA values recorded elsewhere due to the unavailability of ESA values on the particular road section.

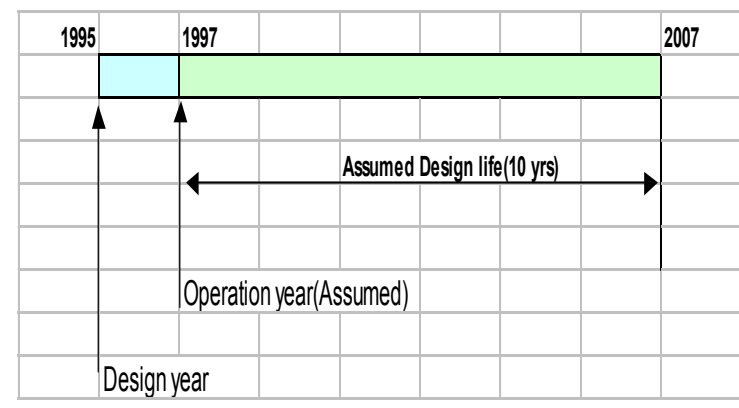

Figure 1 - Present Practice of Pavement Design/Traffic Forecasting of RDA

\section{Calculation of Actual Traffic Growth Rates}

For each road section, the classified quantities of the traffic (Manual Classified Counts, i.e. 
MCC) for each category of vehicles are collected for both the periods of design stage and in the recent past after the road section is opened for traffic. These are converted to ADT using following factors.

\subsection{Factors Used for Calculation of ADT}

The Planning Division of the RDA, generally use expansion factors to convert MCC to ADT depending on the hours of count of the MCC. Factor; 1.1 and 1.2 are usually used to convert 16 hours and 12 hours MCC to ADT respectively. Traffic volume counted in the manual classified count for a certain time period is expanded to obtain the 24 hours traffic volume using expansion factors derived for each district.

\subsection{Calculation of Cumulative Number of standard Axles (CNSA)}

From the factors derived from the American Association of State Highway and Transportation Officials (ASSHTO) road test which enable the damaging power of axle loads of different magnitudes to be expressed in terms of an equivalent number of standard axle loads, the number of axles of each type of vehicle that will use the road during its design life is equated to an equivalent number of standard axles [8].

The cumulative number of standard axles (CNSA) for the design period can be determined by the expression,

CNSA

$$
=365 \sum_{i=1} \underline{\mathrm{P}}_{i}\left[\left(1+\mathrm{r}_{i}\right)^{\mathrm{n}}-1\right]
$$

Where,

$$
\begin{aligned}
\mathrm{P}_{i}= & \text { number of standard axles } \\
& \text { per day as an average for } \\
& \text { the } 1^{\text {st }} \text { year after } \\
& \text { construction for vehicle } \\
& \text { type } i \\
\mathrm{r}_{i} & \text { rate of growth for vehicle } \\
& \text { type } i
\end{aligned}
$$

$$
\begin{array}{ll}
\mathrm{m} & =\text { number of types of vehicles } \\
\mathrm{n} & =\text { design life in years. }
\end{array}
$$

At the time of pavement design, the predicted number of equivalent standard axles value (Designed CNSA) has been estimated using the traffic volumes (ADT) and the average ESA values of different vehicle categories for the road section concerned assuming that the particular road section would be constructed and in operation after a few years (generally two to three years allowed).

\subsection{Selection of Traffic Class \& Sub Grade Strength Class}

There are eight traffic classes (T1-T8) and six sub grade strength classes (S1-S6) given in TRL, Road Note 31 (DOE, 1993). The traffic class relevant to calculated CNSA can be selected accordingly. Similarly, sub grade class also can be selected as the CBR of sub grade is known

\section{Methodology}

In this research study, flexible pavement designs of recently rehabilitated or improved set of roads were analyzed to check the effectiveness of the traffic forecasting on pavement design. As the sub-grade strength of the pavements is a fixed parameter in all the cases, the only possible variable is the Traffic Class relevant to predicted CNSA. In order to test the reliability of the prediction of CNSA, three Scenarios were selected. They were selected based on the Equivalent Standard Axle (ESA), Manual Classified Counts (MCC) and Average Daily Traffic (ADT) data. Recent ADT data and design ADT are associated in the actual traffic growth rates.

The local funded and foreign funded roads are analyzed separately because the traffic growth factors used for foreign funded roads are different to local funded roads(as they are two different parties) and also there are slight changes in calculating the pavement layers. So the main data required for this study is recent ADT and recent ESA values of vehicle types for each selected road section. The other data required are number of lanes, last improvement \& date of improvement and the design data (i.e. design method, year, design life, ADT, predicted year of operation, actual year of operation, predicted vehicle growth 
rate, design CNSA and design pavement layers).

Since the actual date (year) of operation after rehabilitation / improvement is now known, a more realistic prediction could be made using a new set of data. As such, a new CNSA was calculated for the same design life. This was counted from the actual date of operation using the following scenarios.

\section{Scenario - 1:}

Calculation of CNSA using recent data (recent ADT \& ESA values) and with same (predicted $r \%$ ), traffic growth rate used for the design (i.e. CNSA supposed to be carried during the rest of the life).

\section{Scenario - 2:}

Calculation of CNSA using design data (ADT \& ESA values used for the design) and with actual traffic growth rate calculated.

\section{Scenario - 3:}

Calculation of CNSA using recent data (recent ADT \& ESA values) and with actual traffic growth rate calculated.

\section{Analysis of Results}

ADT data at the design stage is essential to calculate the traffic growth rate. There were many road designs, which could not be selected, as some of the necessary information was not given in the design reports. The inclusion of ADT and ESA values at the design stage are very important. Key information should be given not only for research studies of this nature, but also for the correct engineering application at the time of pavement construction.

Specially, under this study, other problems encountered were the non availability of date of design and anticipated period of construction. These two dates or the years are required to calculate the CNSA values under different scenarios. Therefore, collected data were analyzed with respect to the particular road section in the following manner;

a) Comparison of actual traffic growth rates against the predicted rate using ADT \& MCC data.

b) Comparison of ESA values used for the design with the recent ESA values. c) Comparison of cumulative number of standard axles (CNSA) calculated under three different scenarios against the design cumulative number of standard axle.

\subsection{Comparison of Actual Traffic Growth Rates}

The calculated traffic growth factors for local funded roads are given in Table 1. Growth rates for the medium and heavy goods vehicles used for the design and the actual values are shown in figure 2. For the local funded roads, the predicted traffic growth rate used for the designs was 5\%, except for the Dehiwala-Maharagama road for which $10 \%$ growth rate has been selected.

The calculated traffic growth factors for ADB funded roads are tabulated in Table 2. Three different growth factors have been used for the calculation of CNSA at the design stage. These growth factors have been derived from the analysis done in the feasibility study. They are as follows;

i) Growth factor for the period, up to and including the year 2010 .

ii) Growth factor for the period, from the year 2011 to the end of the design life.

iii) Growth factor for generated traffic at completion of the road.

Similarly, actual growth factors for each vehicle category was calculated for the period between the operation of new surface and the end of design life using the ADT data collected from Planning Division of RDA. Growth factors for large and articulated trucks of the ADB funded road sections are shown in Figure 3.

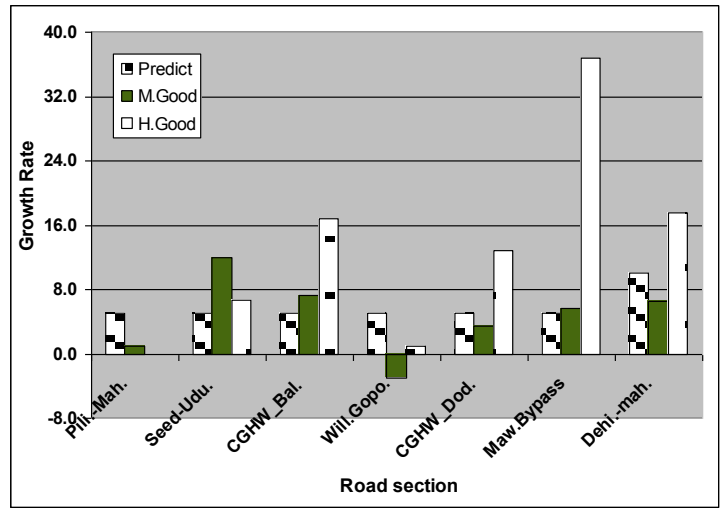

Figure 2 - Traffic growth rates of medium goods vehicles and heavy vehicles on local funded roads 


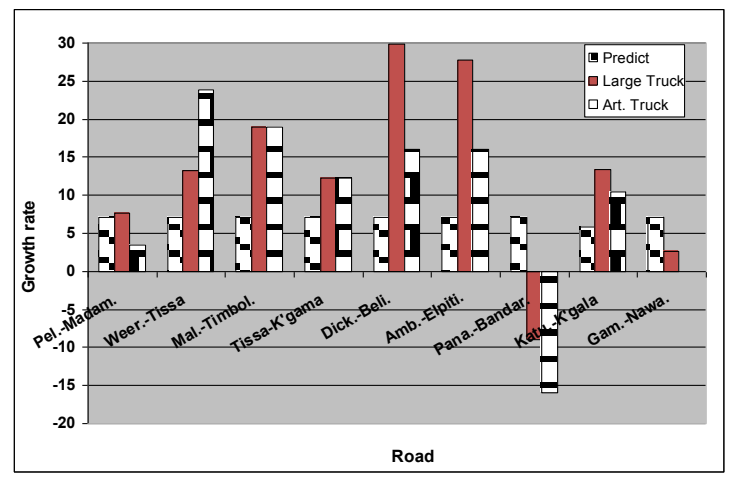

Figure 3 - Traffic growth rates of large trucks and articulated trucks- ADB funded roads

Predicted growth factor for the medium bus was $8.9 \%$ for the period up to 2010 and it was 7\% between 2011 and the end of the design life, for all the roads except on the Katugastota - Kurunegala Road. For that road section, it was $7.3 \%$ and $5.7 \%$ respectively. For the large bus, predicted growth factor for the period up to 2010 was $5.2 \%$ and it was $4 \%$ for the period between 2011 and end of the design life, whereas for the Katugastota - Kurunegala Road, it was $4.2 \%$ \& $3.3 \%$ respectively. Actual growth factor calculated for medium bus is negative for all the roads in the selected set of roads except on the Gampola - Nawalapitiya Road which is $1.7 \%$. The actual growth factor for large bus is greater than the predicted growth factor. The reason for the above observations is that passenger transport regulations have imposed a ban on small buses on the roads and to replace them with large buses.

For the small trucks, predicted growth factor for the respective periods are $9.8 \%$ and $7.7 \%$ except on the Katugastota - Kurunegala Road (i.e. it is $5.5 \%$ and $4.3 \%$ ). It seems that the actual growth factor for small trucks are higher than predicted rates, whilst it is less than the predicted growth rates for large trucks. It was expected that the usage of three axle trucks and articulated trucks would be increasing at and above $5.0 \%$ rate, over its design life, on the road sections once those are improved or rehabilitated. The results show that the actual growth factors for both three axle and articulated trucks are significantly higher than predicted growth rates except for a couple of road sections. This has been proved statistically, that there is a significance difference at the $5 \%$ significance level between the actual and predicted growth rates for both 3-axle and articulated trucks.
Predicted growth factor for the medium bus was $8.9 \%$ for the period up to 2010 and it was 7\% between 2011 and the end of the design life, for all the roads where on the Katugastota - Kurunegala Road. For that road section, it was $7.3 \%$ and $5.7 \%$ respectively. For the large bus, predicted growth factor for the period up to 2010 was $5.2 \%$ and it was $4 \%$ for the period between 2011 and end of the design life, whereas for the Katugastota - Kurunegala Road, it was $4.2 \%$ \& $3.3 \%$ respectively. Actual growth factor calculated for medium bus is negative for all the roads in the selected set of roads except on the Gampola - Nawalapitiya Road which is $1.7 \%$. The actual growth factor for large bus is greater than the predicted growth factor. The reason for the above observations is that, passenger transport regulations have imposed a ban on small buses on the roads and to replace them with large buses. The negative growth factors are rarely obtained (as shown in Figures 2 \& 3) when the recorded count for a particular type of vehicle is less than the previous year/years count for same.

For the small trucks, predicted growth factor for the respective periods are $9.8 \%$ and $7.7 \%$ except on the Katugastota - Kurunegala Road (i.e. it is $5.5 \%$ and $4.3 \%$ ). It seems that the actual growth factors for small trucks are higher than predicted rates, whilst it is less than predicted growth rates for large trucks. It has been expected that the usage of three axle trucks and articulated trucks would be increasing at and above $5.0 \%$ rate, over its design life, on the road sections once those are improved or rehabilitated. The results show that the actual growth factors for both three axle and articulated trucks are significantly higher than predicted growth rates except for a couple of road sections. This has been proved statistically, that there is a significance difference at the $5 \%$ significance level between the actual and predicted growth rates for both 3 -axle and articulated trucks.

\subsection{Comparison of ESA Values}

The ESA values obtained from recent axle load surveys for the different vehicle categories, for the local funded road links are tabulated in Table 3. ESA values of medium and heavy goods vehicles used for the design and the actual values of same for the local funded roads are shown in Figure 4. 
As discussed previously, small buses on the road links are significantly less and hence, the Planning Division of RDA is reluctant to measure axle loads of small buses. Hence, most of the time, ESA values are not measured for small buses. ESA values of large buses seem to be almost equal to the ESA values recorded at the design stage. It has been statistically proved using 5\% level of significance that the ESA values measured during recent axle load surveys for the medium goods vehicles and for the heavy goods vehicles are significantly higher compared to the values used at the design stage. This is an important finding in respect of the pavement strength as the damaging effect for the pavement is more than four times when ESA exceeds the value one.

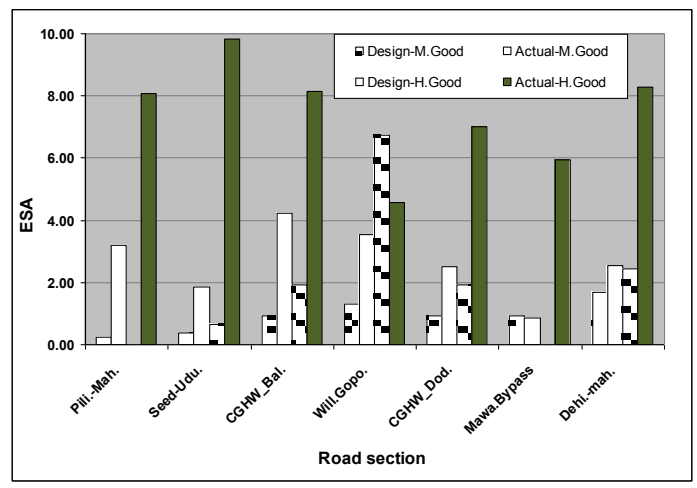

Figure 4 - ESA values of medium and Heavy goods vehicles - local funded roads
The ESA values calculated from the measurements taken during axle load surveys carried out in the recent past, for the different vehicle categories, for the ADB funded road links are tabulated in Table 4. ESA values used for the design and the actual values for large and articulated trucks are shown in Figure 5.

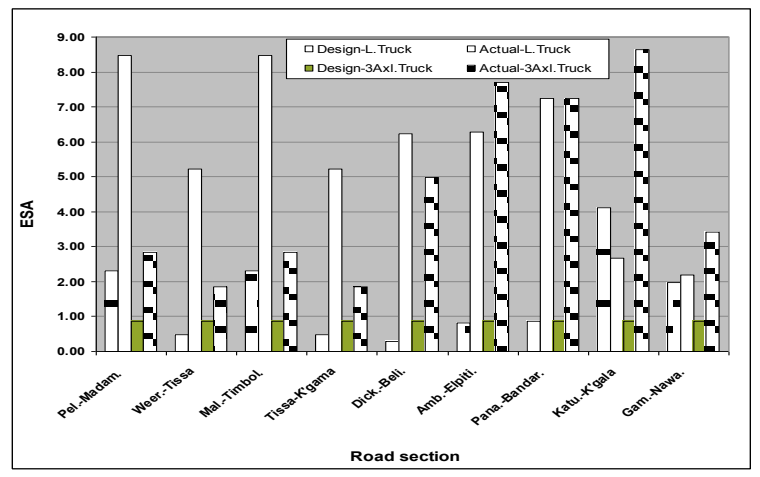

Figure 5 - ESA Values of Large \& Articulated Trucks- ADB Funded Roads

Table 1 - Traffic Growth Factors - Local Funded Roads

\begin{tabular}{|c|c|c|c|c|c|c|c|c|}
\hline \multirow{2}{*}{$\begin{array}{l}\text { Item } \\
\text { No. }\end{array}$} & \multirow[t]{2}{*}{ Road Name } & \multirow[t]{2}{*}{ Status } & \multicolumn{6}{|c|}{ Vehicle Category } \\
\hline & & & $\begin{array}{l}\text { Mediu } \\
\text { m Bus }\end{array}$ & $\begin{array}{c}\text { Large } \\
\text { Bus }\end{array}$ & $\begin{array}{c}\text { Large } \\
\text { Goods } \\
\text { veh }\end{array}$ & $\begin{array}{c}\text { Medium } \\
\text { Goods } \\
\text { veh }\end{array}$ & $\begin{array}{c}\text { Heavy } \\
\text { Goods } \\
\text { veh }\end{array}$ & Cars \\
\hline \multirow[b]{2}{*}{1} & \multirow{2}{*}{ Piliyandala - Maharagama Rd. } & Predicted & 5.0 & 5.0 & 5.0 & 5.0 & 5.0 & 5.0 \\
\hline & & Actual & 6.0 & 2.4 & 0.6 & 1.0 & 12.2 & 0.1 \\
\hline \multirow[b]{2}{*}{2} & \multirow{2}{*}{ Seeduwa - Udugampola Rd. } & Predicted & 5.0 & 5.0 & 5.0 & 5.0 & 5.0 & 5.0 \\
\hline & & Actu & -10.2 & 0.5 & 0.6 & 12.0 & 6.7 & - \\
\hline \multirow[b]{2}{*}{3} & \multirow{2}{*}{ CGHW Road at Balapitiya } & Predicted & 5.0 & 5.0 & 5.0 & 5.0 & 5.0 & 5.0 \\
\hline & & Actu & -7.2 & 4.7 & 1.1 & 6.2 & 26.1 & - \\
\hline \multirow[b]{2}{*}{4} & \multirow{2}{*}{ William Gopallawa Mw. Kdy. } & Predicted & 5.0 & 5.0 & 5.0 & 5.0 & 5.0 & 5.0 \\
\hline & & Actual & -20.8 & 3.9 & -7.6 & -3.0 & 0.9 & 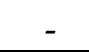 \\
\hline \multirow[b]{2}{*}{5} & \multirow{2}{*}{ CGHW Road at Dodanduwa } & Predicted & 5.0 & 5.0 & 5.0 & 5.0 & 5.0 & 5.0 \\
\hline & & Actual & -1.0 & 2.2 & -2.3 & 3.5 & 12.8 & - \\
\hline \multirow[b]{2}{*}{6} & \multirow{2}{*}{ Mawanella Bypass } & Predicted & 5.0 & 5.0 & 5.0 & 5.0 & 5.0 & 5.0 \\
\hline & & Actual & -9.2 & -12.3 & -7.6 & 4.3 & 35.0 & - \\
\hline \multirow[b]{2}{*}{7} & \multirow{2}{*}{ Dehiwala - Maharagama Rd. } & Predicted & 10.0 & 10.0 & 10.0 & 10.0 & 10.0 & 10.0 \\
\hline & & Actual & -29.4 & 4.9 & -13.3 & -4.1 & 9.4 & \\
\hline
\end{tabular}


Table 2 - Traffic Growth Factors - ADB Funded Roads

\begin{tabular}{|c|c|c|c|c|c|c|c|c|}
\hline \multirow{2}{*}{$\begin{array}{l}\text { Item } \\
\text { No. }\end{array}$} & \multirow[t]{2}{*}{ Road Name } & \multirow[t]{2}{*}{ Stage } & \multicolumn{6}{|c|}{ Vehicle Category } \\
\hline & & & $\begin{array}{c}\text { Medium } \\
\text { Bus }\end{array}$ & $\begin{array}{l}\text { Large } \\
\text { Bus }\end{array}$ & $\begin{array}{l}\text { Small } \\
\text { Truck }\end{array}$ & $\begin{array}{l}\text { Large } \\
\text { Truck }\end{array}$ & $\begin{array}{l}\text { 3-Axle } \\
\text { truck }\end{array}$ & $\begin{array}{l}\text { Articu. } \\
\text { Truck }\end{array}$ \\
\hline \multirow[b]{3}{*}{1} & \multirow{3}{*}{$\begin{array}{l}\text { Pelmadulla-Madampe } \\
\text { Road (C-11) }\end{array}$} & upto 2010 & 8.90 & 5.20 & 9.80 & 6.70 & 7.10 & 7.10 \\
\hline & & 2011-End & 7.00 & 4.00 & 7.70 & 5.20 & 5.50 & 6.60 \\
\hline & & Actual & -6.80 & 16.10 & 10.70 & 0.40 & 7.60 & 3.40 \\
\hline \multirow[b]{3}{*}{2} & \multirow{3}{*}{$\begin{array}{l}\text { Weerawila-Kataragama } \\
(C-10,1)\end{array}$} & upto 2010 & 8.90 & 5.20 & 9.80 & 6.70 & 7.10 & 7.10 \\
\hline & & 2011-End & 7.00 & 4.00 & 7.70 & 5.20 & 5.50 & 6.60 \\
\hline & & Actual & -6.50 & -3.60 & -12.60 & 3.00 & 13.20 & 23.80 \\
\hline \multirow[b]{3}{*}{3} & \multirow{3}{*}{$\begin{array}{l}\text { Malwatte, G'wela to } \\
\text { Timbolketiya Rd.(C-13) }\end{array}$} & upto 2010 & 8.90 & 5.20 & 9.80 & 6.70 & 7.10 & 7.10 \\
\hline & & 2011-End & 7.00 & 4.00 & 7.70 & 5.20 & 5.50 & 6.60 \\
\hline & & Actual & -9.90 & 8.20 & 8.70 & 2.10 & 18.90 & 18.90 \\
\hline \multirow[b]{3}{*}{4} & \multirow{3}{*}{$\begin{array}{l}\text { Tissa-Kataragama } \\
(\mathrm{C}-10,2)\end{array}$} & upto 2010 & 8.90 & 5.20 & 9.80 & 6.70 & 7.10 & 7.10 \\
\hline & & 2011-End & 7.00 & 4.00 & 7.70 & 5.20 & 5.50 & 6.60 \\
\hline & & Actual & -11.60 & 4.00 & 4.20 & -1.60 & 12.20 & 12.20 \\
\hline \multirow[b]{3}{*}{5} & \multirow{3}{*}{$\begin{array}{l}\text { Dickwella-Beliatta } \\
(\mathrm{C}-10,3)\end{array}$} & upto 2010 & 8.90 & 5.20 & 9.80 & 6.70 & 7.10 & 7.10 \\
\hline & & 2011-End & 7.00 & 4.00 & 7.70 & 5.20 & 5.50 & 6.60 \\
\hline & & Actual & -8.20 & 7.40 & 18.40 & 2.60 & 29.90 & 16.10 \\
\hline \multirow[b]{3}{*}{6} & \multirow{3}{*}{$\begin{array}{l}\text { Ambalangoda-Elpitiya } \\
\text { (C-5) }\end{array}$} & upto 2010 & 8.90 & 5.20 & 9.80 & 6.70 & 7.10 & 7.10 \\
\hline & & 2011-End & 7.00 & 4.00 & 7.70 & 5.20 & 5.50 & 6.60 \\
\hline & & Actual & -10.60 & 6.90 & 10.40 & 6.30 & 27.80 & 16.1 \\
\hline \multirow[b]{3}{*}{7} & \multirow{3}{*}{$\begin{array}{l}\text { Panadura-Rathnapura } \\
\text { Rd. (C-3) }\end{array}$} & upto 2010 & 8.90 & 5.20 & 9.80 & 6.70 & 7.10 & 7.10 \\
\hline & & 2011-End & 7.00 & 4.00 & 7.70 & 5.20 & 5.50 & 6.60 \\
\hline & & Actual & -8.80 & 15.70 & 12.70 & 6.60 & 24.6 & 14.9 \\
\hline & \multirow{3}{*}{$\begin{array}{l}\text { Katugastota-Kurunegala } \\
\text { (C-7) }\end{array}$} & upto 2010 & 7.30 & 4.20 & 8.00 & 5.50 & 5.80 & 5.80 \\
\hline & & 2011-End & 5.70 & 3.30 & 6.30 & 4.30 & 4.50 & 5.40 \\
\hline 8 & & Actual & -7.30 & 9.80 & 8.80 & 2.50 & 13.40 & 10.50 \\
\hline & \multirow{3}{*}{$\begin{array}{l}\text { Gampola-Nawalapitiya } \\
\text { (C-8) }\end{array}$} & upto 2010 & 8.90 & 5.20 & 9.80 & 6.70 & 7.10 & 7.10 \\
\hline & & 2011-End & 7.00 & 4.00 & 7.70 & 6.30 & 6.60 & 7.90 \\
\hline 9 & & Actual & 1.70 & 11.80 & 10.30 & 11.70 & 2.60 & - \\
\hline
\end{tabular}


Table 3 - ESA Values - Locally Funded Roads

\begin{tabular}{|c|c|c|c|c|c|c|c|}
\hline \multirow{2}{*}{$\begin{array}{l}\text { Item } \\
\text { No. }\end{array}$} & \multirow[t]{2}{*}{ Road Name } & \multirow[t]{2}{*}{ Stage } & \multicolumn{5}{|c|}{ Vehicle Category } \\
\hline & & & $\begin{array}{c}\text { Medium } \\
\text { Bus }\end{array}$ & $\begin{array}{l}\text { Large } \\
\text { Bus }\end{array}$ & $\begin{array}{c}\text { Large } \\
\text { Goods } \\
\text { Veh }\end{array}$ & $\begin{array}{c}\text { Medium } \\
\text { Goods } \\
\text { veh }\end{array}$ & $\begin{array}{c}\text { Heavy } \\
\text { Goods } \\
\text { veh. }\end{array}$ \\
\hline \multirow[b]{2}{*}{1} & \multirow{2}{*}{ Piliyandala - Maharagama Road } & Design & 0.013 & 0.444 & 0.003 & 0.229 & _ \\
\hline & & Current & - & 0.400 & 0.321 & 3.181 & 8.090 \\
\hline \multirow[b]{2}{*}{2} & \multirow{2}{*}{ Seeduwa - Udugampola road } & Design & 0.049 & 0.200 & 0.045 & 0.370 & 0.640 \\
\hline & & Current & - & 0.400 & 0.321 & 1.860 & 9.843 \\
\hline \multirow[b]{2}{*}{3} & \multirow{2}{*}{ CGHW Road at Balapitiya } & Design & 0.019 & 0.329 & 0.176 & 0.918 & 1.925 \\
\hline & & Current & 0.020 & 0.438 & - & 4.220 & 8.141 \\
\hline \multirow[b]{2}{*}{4} & \multirow{2}{*}{ William Gopallawa Mw. Kandy } & Design & 0.103 & 0.704 & 0.036 & 1.316 & 6.728 \\
\hline & & Current & - & 0.580 & 0.003 & 3.537 & 4.578 \\
\hline \multirow[b]{2}{*}{5} & \multirow{2}{*}{ CGHW Road at Dodanduwa } & Design & 0.019 & 0.329 & 0.176 & 0.918 & 1.925 \\
\hline & & Current & 0.017 & 0.376 & 0.001 & 2.509 & 7.000 \\
\hline \multirow[b]{2}{*}{6} & \multirow{2}{*}{ Mawanella Bypass } & Design & 0.020 & 0.400 & 0.176 & 0.918 & 0.000 \\
\hline & & Current & 0.169 & 0.400 & 0.010 & 0.864 & 5.950 \\
\hline \multirow[b]{2}{*}{7} & \multirow{2}{*}{ Dehiwala - Maharagama Road } & Design & 0.170 & 0.320 & 0.010 & 1.680 & 2.450 \\
\hline & & Current & 0.013 & 0.370 & 0.105 & 2.563 & 8.290 \\
\hline
\end{tabular}

Table 4 - ESA Values - Foreign Funded Roads

\begin{tabular}{|c|c|c|c|c|c|c|c|c|}
\hline \multirow{2}{*}{$\begin{array}{l}\text { Item } \\
\text { No. }\end{array}$} & \multirow[t]{2}{*}{ Road Name } & \multirow[t]{2}{*}{ Stage } & \multicolumn{6}{|c|}{ Vehicle Category } \\
\hline & & & $\begin{array}{c}\text { Medium } \\
\text { Bus }\end{array}$ & $\begin{array}{l}\text { Large } \\
\text { Bus }\end{array}$ & $\begin{array}{l}\text { Small } \\
\text { Truck }\end{array}$ & $\begin{array}{c}\text { L.Truc } \\
\mathrm{k}\end{array}$ & $\begin{array}{l}\text { 3-Axle } \\
\text { truck }\end{array}$ & $\begin{array}{l}\text { Articu. } \\
\text { Truck }\end{array}$ \\
\hline \multirow[b]{2}{*}{1} & \multirow{2}{*}{$\begin{array}{l}\text { Pelmadulla-Madampe } \\
\text { Road (C-11) }\end{array}$} & Design & 0.045 & 0.146 & 0.035 & 2.323 & 0.867 & 1.001 \\
\hline & & Current & 0.007 & 0.340 & 0.048 & 8.465 & 2.850 & 4.480 \\
\hline \multirow[b]{2}{*}{2} & \multirow{2}{*}{$\begin{array}{l}\text { Weerawila-Kataragama } \\
(\mathrm{C}-10,1)\end{array}$} & Design & 0.037 & 0.193 & 0.152 & 0.465 & 0.867 & 1.001 \\
\hline & & Current & - & 0.368 & 0.003 & 5.215 & 1.865 & 6.166 \\
\hline \multirow[b]{2}{*}{3} & \multirow{2}{*}{$\begin{array}{l}\text { Malwatte,Godakawela to } \\
\text { Timbolketiya Road (C-13) }\end{array}$} & Design & 0.045 & 0.146 & 0.035 & 2.323 & 0.867 & 1.001 \\
\hline & & Current & 0.007 & 0.340 & 0.048 & 8.465 & 2.850 & 4.480 \\
\hline \multirow[b]{2}{*}{4} & \multirow{2}{*}{ Tissa-Kataragama (C-10,2) } & Design & 0.037 & 0.193 & 0.152 & 0.465 & 0.867 & 1.001 \\
\hline & & Current & - & 0.368 & 0.003 & 5.215 & 1.865 & 6.166 \\
\hline \multirow[b]{2}{*}{5} & \multirow{2}{*}{$\begin{array}{l}\text { Dickwella-Beliatta } \\
(\mathrm{C}-10,3)\end{array}$} & Design & 0.026 & 0.076 & 0.008 & 0.282 & 0.867 & 1.001 \\
\hline & & Current & 0.021 & 0.439 & 0.096 & 6.238 & 4.987 & - \\
\hline \multirow[b]{2}{*}{6} & \multirow{2}{*}{$\begin{array}{l}\text { Ambalangoda-Elpitiya } \\
(\mathrm{C}-5)\end{array}$} & Design & 0.016 & 0.057 & 0.011 & 0.810 & 0.867 & 1.001 \\
\hline & & Current & 0.017 & 0.376 & 0.309 & 6.285 & 7.714 & - \\
\hline \multirow[b]{2}{*}{7} & \multirow{2}{*}{$\begin{array}{l}\text { Panadura-Rathnapura } \\
\text { Road (C-3) }\end{array}$} & Design & 0.065 & 0.216 & 0.093 & 3.224 & 0.867 & 1.001 \\
\hline & & Current & 0.020 & 0.438 & 0.222 & 5.163 & 7.250 & 9.136 \\
\hline \multirow[b]{2}{*}{8} & \multirow{2}{*}{$\begin{array}{l}\text { Katugastota-Kurunegala } \\
\text { (C-7) }\end{array}$} & Design & 0.115 & 0.450 & 0.162 & 4.115 & 0.867 & 1.001 \\
\hline & & Current & 0.033 & 0.620 & 0.220 & 2.670 & 8.640 & 14.900 \\
\hline \multirow[b]{2}{*}{9} & \multirow{2}{*}{$\begin{array}{l}\text { Gampola-Nawalapitiya } \\
\text { (C-8) }\end{array}$} & Design & 0.080 & 0.331 & 0.071 & 1.981 & 0.867 & 1.001 \\
\hline & & Current & 0.034 & 0.432 & 0.165 & 2.190 & 3.418 & 5.886 \\
\hline
\end{tabular}


Similarly, in the local funded road links, ESA values recorded for the medium bus is less than the ESA values recorded at the design stage. However, ESA values of large buses and small trucks are slightly higher than the ESA values recorded at the design stage. It has been statistically proved that the ESA values of large trucks are significantly high compared to the values recorded at the design stage. This is a very important fact, mainly because of the number of large trucks using; 'A' \& ' $B$ ' class roads are generally high and thereby create a tendency to damage the pavement structure before the end of its design life.

It has also been statistically proved that recent ESA values calculated for the three axle trucks and articulated trucks are significantly high compared to the ESA values at design stage. However, this may not be a fact that can be highlighted as the ESA values used for the design are default values. These default ESA values have been applied when the total number of a particular vehicle type was less than 10. This default ESA factor was calculated from the average measured values on roads where the number of vehicles weighed was greater than 10 .

\subsection{Comparison of Cumulative Number of Standard Axle (CNSA) Values}

As discussed in the Methodology, Cumulative Number of Standard Axles (CNSA) that would carry or supposed to carry over the rehabilitated or improved pavement were calculated under three (03) different scenarios.

Scenario 1 associates the present condition of traffic and it gives an indication as to what would be the result if the present condition of traffic continues at the predicted rate. It also indicates that, for the $90 \%$ of the selected road sections, the CNSA of scenario 1 is higher than the design CNSA.

Scenario 2 associates the design data and the actual growth rates, and it is applied over the actual design life. Its CNSA values are almost close to the design CNSA.
Scenario 3 represents the present condition of traffic and also the actual growth rate. The CNSA values of it are higher compared to the design CNSA.

Comparison of CNSA values calculated under each scenario against the designed CNSA, is done for the local funded roads and for ADB funded roads separately

The CNSA values calculated under each scenario for the local funded roads are shown in the Table 5. The relevant traffic class with respect to the CNSA value and its traffic class is also given for each road section for comparison purposes. As shown in Table 5, except for the two roads section (i.e. William Gopallawa Mawatha, Kandy and Mawanella Bypass Road) traffic class of Scenario-1 is higher than the design traffic class.

It also shows that the traffic class of Scenario-3 is higher than that of design traffic class, except for the William Gopallawa Mawatha and Dehiwala-Maharagama roads.

As discussed earlier, the ADT used for the design of William Gopallawa Mawatha road was over estimated. For the DehiwalaMaharagama road, the predicted traffic growth rate for the design is twice compared to others (i.e. $r=10 \%$ ). These are the probable reasons for the above two exceptions.

A similar analysis could be done for the ADB funded roads too, as per the results shown in Table 6. Except for two road sections, the traffic class of Scenario-3 is higher than that of design traffic class. The CNSA values calculated under each Scenario for the ADB funded roads are shown in Table 6. 
Table 5 - CNSA Values of Each Scenario - Local Funded Roads

\begin{tabular}{|c|c|c|c|c|c|c|c|}
\hline Road Name & 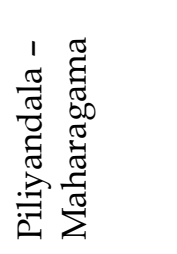 & 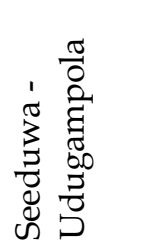 & 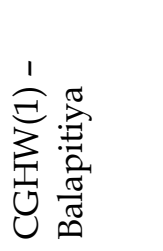 & 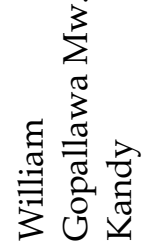 & 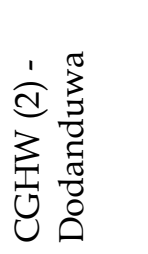 & 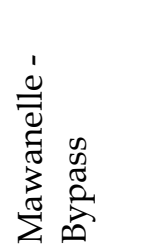 & 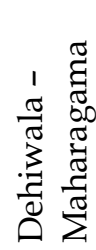 \\
\hline CNSA designed & $\begin{array}{l}0.75 \\
\text { (T3) }\end{array}$ & $\begin{array}{l}0.73 \\
\text { (T3) }\end{array}$ & $\begin{array}{c}3.9 \\
\text { (T5) }\end{array}$ & $\begin{array}{l}7.35 \\
\text { (T6) }\end{array}$ & $\begin{array}{c}3.6 \\
(\mathrm{~T} 5)\end{array}$ & $\begin{array}{c}8.8 \\
\text { (T6) }\end{array}$ & $\begin{array}{l}9.65 \\
(\mathrm{~T} 6)\end{array}$ \\
\hline $\begin{array}{c}\text { CNSA - } \\
\text { Scenario-1 }\end{array}$ & $0.92(\mathrm{~T} 4)$ & 8.61(T6) & 10.15(T7) & 7.23(T6) & 6.8(T6) & $5.22(\mathrm{~T} 5)$ & $\begin{array}{l}12.9 \\
\text { (T7) }\end{array}$ \\
\hline $\begin{array}{c}\text { CNSA - } \\
\text { Scenario-2 }\end{array}$ & $0.83(\mathrm{~T} 3)$ & 1.18(T3) & $2.69(\mathrm{~T} 4)$ & 5.4(T5) & 3.61(T5) & $5.56(\mathrm{~T} 5)$ & $\begin{array}{l}6.09 \\
\text { (T6) }\end{array}$ \\
\hline $\begin{array}{c}\text { CNSA - } \\
\text { Scenario-3 }\end{array}$ & 13.68(T7) & 14.27(T7) & 14.67(T7) & 5.91(T5) & $7.23(\mathrm{~T} 6)$ & $15.08(\mathrm{~T} 7)$ & $\begin{array}{l}9.57 \\
\text { (T6) }\end{array}$ \\
\hline
\end{tabular}

Table 6 - CNSA Values of Each Scenario - ADB Funded Roads

\begin{tabular}{|c|c|c|c|c|c|c|c|c|c|}
\hline Road Name & 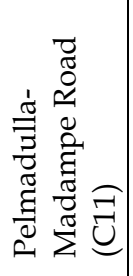 & 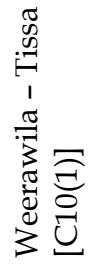 & 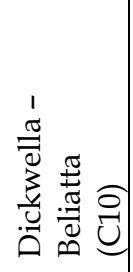 & 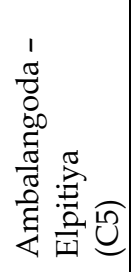 & 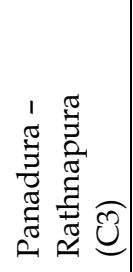 & 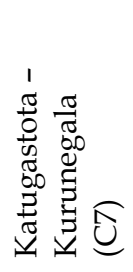 & 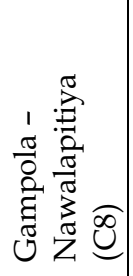 & 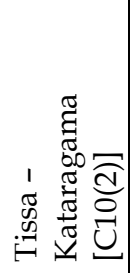 & 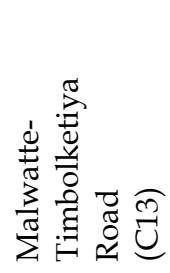 \\
\hline $\begin{array}{l}\text { CNSA } \\
\text { Design }\end{array}$ & $\begin{array}{l}4.98 \\
\text { (T5) } \\
\end{array}$ & $\begin{array}{l}0.34 \\
\text { (T2) }\end{array}$ & $\begin{array}{c}0.0 \\
(\mathrm{~T} 1)\end{array}$ & $\begin{array}{c}0.0 \\
(\mathrm{~T} 1)\end{array}$ & $\begin{array}{l}8.88 \\
\text { (T6) }\end{array}$ & $\begin{array}{l}8.67 \\
\text { (T6) }\end{array}$ & $\begin{array}{l}5.00 \\
\text { (T5) }\end{array}$ & $\begin{array}{l}0.48 \\
\text { (T2) }\end{array}$ & 3.9 (T5) \\
\hline $\begin{array}{c}\text { CNSA - } \\
\text { Scenario-1 }\end{array}$ & $\begin{array}{l}9.66 \\
\text { (T6) }\end{array}$ & $\begin{array}{l}1.49 \\
\text { (T3) }\end{array}$ & $\begin{array}{l}3.13 \\
\text { (T5) }\end{array}$ & $\begin{array}{l}4.48 \\
\text { (T5) }\end{array}$ & $\begin{array}{c}16.57 \\
\text { (T7) }\end{array}$ & $\begin{array}{l}6.8 \\
(\mathrm{~T} 6)\end{array}$ & $\begin{array}{c}11.53 \\
\text { (T7) }\end{array}$ & $\begin{array}{c}0.9 \\
\text { (T3) }\end{array}$ & 8.25 (T6) \\
\hline $\begin{array}{l}\text { CNSA - } \\
\text { Scenario-2 }\end{array}$ & $\begin{array}{l}3.21 \\
\text { (T5) }\end{array}$ & $\begin{array}{l}0.12 \\
\text { (T1) }\end{array}$ & $\begin{array}{c}0.0 \\
(\mathrm{~T} 1)\end{array}$ & $\begin{array}{c}0.0 \\
(\mathrm{~T} 1)\end{array}$ & $\begin{array}{l}6.98 \\
\text { (T6) }\end{array}$ & $\begin{array}{l}8.16 \\
\text { (T6) }\end{array}$ & $\begin{array}{l}7.39 \\
\text { (T6) }\end{array}$ & $\begin{array}{c}0.0 \\
(\mathrm{~T} 1)\end{array}$ & $2.62(\mathrm{~T} 4)$ \\
\hline $\begin{array}{c}\text { CNSA - } \\
\text { Scenario-3 }\end{array}$ & $\begin{array}{l}10.47 \\
\text { (T7) }\end{array}$ & $\begin{array}{l}1.1 \\
\text { (T3) }\end{array}$ & $\begin{array}{l}6.47 \\
(\mathrm{~T} 6)\end{array}$ & $\begin{array}{l}9.48 \\
(\mathrm{~T} 6)\end{array}$ & - & $\begin{array}{l}8.17 \\
(\mathrm{~T} 6)\end{array}$ & $\begin{array}{c}18.48 \\
\text { (T8) }\end{array}$ & $\begin{array}{l}0.89 \\
\text { (T3) }\end{array}$ & 7.65 (T6) \\
\hline
\end{tabular}




\section{Conclusion}

In this research study, flexible pavement designs of recently rehabilitated or improved set of roads were analyzed to check the effectiveness of the traffic forecasting on pavement design. As the sub-grade strength of the pavements is a fixed parameter in all the cases, the only possible variable is the Traffic Class relevant to predicted CNSA. In order to test the reliability of the prediction of CNSA, the three Scenarios discussed above, were selected

It is better to look back at the three Scenarios discussed above.

Scenario - 1:

Calculation of CNSA (Cumulative Number of Standard Axles) using recent data (i.e. recent ESA \& ADT) and with same traffic growth rate used for the design.(CNSA supposed to carry during the rest of the life)

Scenario - 2:

Calculation of CNSA using design data (ESA

\& ADT used for the design) and with actual traffic growth rate.

Scenario - 3:

Calculation of CNSA using recent data (recent ESA \& ADT) and with actual traffic growth rate.

The above Scenarios were selected based on the ESA and ADT data. Recent ADT data and design MCC / ADT are associated in the actual traffic growth rates.

Following conclusions were made with respect to the actual traffic growth rate and the ESA comparison of each vehicle category.

It was observed that at or above $5 \%$ growth rates were predicted for both medium buses and large buses. The actual traffic growth rate of medium buses was recorded as a negative rate and also for the large buses; actual growth rate is generally less than $5 \%$. The probable reasons for these findings were discussed above.

It can also be concluded that the growth rate of heavy goods vehicles are higher than the predicted rate. So, this study shows that there is an increasing trend of commercial vehicles on the roads. It has also been shown and statistically proved that the ESA values actually applied on these pavements by large trucks / heavy goods vehicles are significantly high, compared to the ESA values recorded at the design stage. This could be an important factor that should be taken into account in the design of pavements as the damaging effect of the pavement increases heavily as the number of heavy vehicles increased. In order, that the pavement designs of the selected road sections to be effective, the above factors or the findings should be reflected in the designs.

Therefore, the most appropriate Scenario which incorporates all the key factors identified above has to be selected out of the three Scenarios to test the effectiveness of traffic forecasting of the selected set of roads. As such, it can be concluded that "Scenario-3" is the most appropriate one to test the effectiveness of traffic forecasting on pavement designs.

For twelve road sections, out of sixteen (i.e.75\%), the traffic class related to Scenario-3 is higher than the design traffic class. Hence, it can be concluded that $75 \%$ of the selected road designs are under designed.

Following recommendations are made in respect of the conclusions made.

i) More emphasis should be given to the estimation of percentage of commercial trucks (heavy goods vehicles).

It is possible that this percentage could substantially change during the period between the actual traffic count and the time of construction.

ii) It is recommended to use more realistic traffic growth rates which are calculated based on the latest ADT data.

iii) As there will be a gap of two to three years or more between the year of design and the year of construction, it is recommended to

re-evaluate the pavement design prior to the construction of a particular road or the section of road concerned with the latest information available.

In order to facilitate the above, following important aspects are proposed to be included in the design report at the design stage.

a) Year / Date of design should be Indicated.

b) Sub-grade class of each section of road should be indicated. 
c) ESA values of each vehicle category used for the design should be indicated

d) Year of ADT / MCC ,expansion factors Used for computation of ADT (if any)and year of axle data should be stated.

e) Predicted year of operation of road pavement should be stated.

f) Design report should be consistent (standard).

Due to the non availability of adequate data this study was restricted to a few road sections. It is noted that, to improve the pavement designs, this should be analysed further. Future studies should include the selection of more road sections, provided the necessary data is available, and using this study as a foundation to build on.

\section{References}

1) Highway Research Board. The AASHO Road Test. Repot 5, Pavement Research Highway Research Board Special Report No. 61E National Research Council, Washington DC. 1962.

2) Paterson, W.D.O., Road Deterioration and Maintenance Effects: Models for Planning and
Management. The Highway Design and Maintenance Standards Series. The International Bank for Reconstruction and Development, Washington DC,1987.

3) DOE, Road Research Laboratory Road Note 31, Fourth Edition, "A Guide to the Structural Design of Bitumen-surfaced roads in Tropical and Sub-tropical Countries" 1993.

4) Millard, R. S., "Road Building in the Tropics" Transport Research Laboratory, Department of Transport, UK. State of the Art Review 9, 1993 PP 231 - 251.

5) Howe, J.D.G.F., A Review of Rural Traffic Counting Methods in Developing Countries, RRL Report LR 427, Road Research Laboratory, Crowthorne, 1972.

6) Road Development Authority, - "A Guide to the Structural Design of Roads under Sri Lanka Conditions", 1999.

7) Road Development Authority, "Standard Specifications for Construction and Maintenance of Roads and Bridges", 1989.

8) Liddle, W.J., "Application of AASHO Road Test Results to the Design of Flexible Pavement Structures". First International Conference on the Structural Design of Asphalt Pavements, University of Michigan, 20-24 August 1962, Anm Arbor, Michigan, 1962 (University of Michigan) 